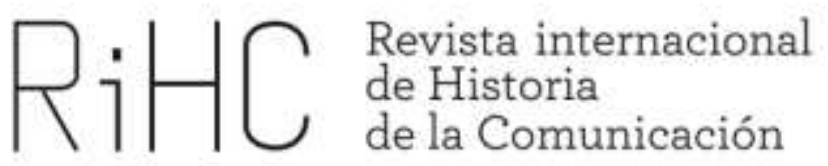

\title{
"LA INVASIÓN DE LOS BÁRBAROS DEL ANUNCIO". UNA HISTORIA DE LA PUBLICIDAD EXTERIOR EN MADRID, 1900-1936
}

DOI: http://dx.doi.org/10.12795/RiHC.2016.i07.03

Nuria Rodríguez Martín ${ }^{1}$

Universidad del País Vasco/Euskal Herriko Unibertsitatea

nuria.rodriguezm@ehu.eus

Recibido: 7-11-2016

Aceptado: 5-12-2016

Resumen: La publicidad exterior es un elemento omnipresente en el paisaje urbano, una realidad que en las últimas décadas se ha convertido en objeto de creciente debate y contestación social. Este artículo estudia los orígenes históricos de la conformación de las urbes occidentales como inmensos soportes publicitarios, a través del caso de Madrid. Se analiza cómo la multiplicación de anuncios en sus vías públicas durante el primer tercio del siglo XX, contribuyó a transformar la imagen de la ciudad y a difundir la nueva cultura de consumo entre la sociedad madrileña de la época.

Palabras clave: Publicidad exterior, polución publicitaria, anuncios, historia de Madrid

\footnotetext{
${ }^{1}$ Este texto ha sido posible por la concesión de un contrato Juan de la Cierva (Ref.: FJCl-2014-20553), y forma parte de las actividades vinculadas al proyecto de investigación "La sociedad urbana en la España del primer tercio del siglo XX. Madrid y Bilbao, vanguardia de la modernidad, 1900-1936" (HAR201565134-C2-2-P) financiado por MINECO/FEDER.
} 
Abstract: Outdoor Advertising is a ubiquitous element in the urban landscape, a subject of intense public discussion in recent years. This paper intends to illustrate the historical process by which Western cities were transformed into enormous advertising canvasses, by showing the case of Madrid. This study tracks the multiplication of ads within the city during the first third of the $20^{\text {th }}$ century, which not only transformed the image of the city, but also was instrumental in the spread of the new consumer culture among the Madrilean society of the time.

Keywords: Outdoor advertising, Advertising pollution, Advertisements, History of Madrid

\section{Introducción}

A finales de 2014 el Ayuntamiento de Grenoble anunció la supresión de la publicidad exterior en esta localidad. La medida incluía la retirada de 326 soportes publicitarios instalados en sus vías públicas y la no renovación del contrato por el que se adjudicaba hasta entonces la explotación de la publicidad en el municipio. La conocida como capital de los Alpes franceses se convertía en la primera ciudad europea que retiraba de sus calles los anuncios comerciales, en el marco de un amplio plan de desarrollo urbano ideado para acometer una "tercera revolución urbana" que la transformara en un "nuevo espacio de vida", según declaró su alcalde. ${ }^{2}$ Antes que Grenoble en Europa, otras municipalidades como las de San Paulo, Nueva York y Tokio, habían adoptado medidas similares con objeto de reducir el número de anuncios publicitarios en sus vías públicas, buscando aminorar la contaminación visual y el impacto que esos elementos tienen en la estética y en el paisaje urbano. Estas actuaciones, que no dejan de ser limitadas y en modo alguno suprimen por completo la publicidad en las calles, responden en buena medida a una creciente sensibilización ciudadana a una publicidad considerada cada vez más invasiva; No tanto por el volumen de anuncios, como por lo que se juzga como un uso indebido del espacio público, cuando éste se pone al servicio de los intereses particulares -los de los anunciantes -en vez de servir a los generales (Mattelart, 1991; Cronin, 2006). Esta sensibilidad ha ido creciendo en las últimas décadas debido al eco alcanzado por las denuncias de algunos artistas y activistas, así como de distintos colectivos movilizados contra el consumismo ${ }^{3}$, y en

\footnotetext{
${ }^{2}$ Entrevista a Éric Piolle en el canal France 24 Disponible en internet (Consultado: 24-10-2015) http://www.france24.com/fr/20151024-grenoble-marche-troisieme-revolution-environnement-ericpiolle-vert-ecologiste-eelv

${ }^{3}$ La mayoría de grupos, colectivos y artistas del movimiento anti publicidad como Public Ad Campaign Brandalism, Vermibus, Poster Boy, OX... cuentan con sitios webs donde ofrecen información sobre su filosofía y actividades.
} 
favor de ciudades libres de publicidad y, por ello, menos agresivas para sus habitantes (Olivares, 2001; Méndez Velandia, 2013; Portella, 2014).

España no ha permanecido ajena a este movimiento de carácter global, aunque su fuerza y visibilidad hayan tenido un carácter más limitado respecto a otros países. Aunque de forma puntual, algunas medidas relacionadas con la publicidad en los espacios públicos han suscitado protestas por parte de la ciudadanía, divulgadas por la prensa y a través de las redes sociales. Como las que se produjeron en 2013 con motivo del naming de la línea 2 del Metro de Madrid y su emblemática estación de Sol (Pacheco Rueda, 2014), renombradas por una compañía de telecomunicaciones. El escritor Antonio Muñoz Molina se sumó a las críticas contra esta iniciativa con un duro artículo en el diario El País en el que escribió:

Hay que tener una idea muy bárbara de lo que es la vida ciudadana para vender a compañías privadas los nombres de los espacios y los servicios públicos; Privatizar el nombre de una línea de metro llamándole 'Vodafone' es una usurpación de algo tan colectivo y público por naturaleza como el aire de la calle, como las palabras del idioma (Muñoz Molina, 2014).

Por esa y otras actuaciones, la capital de España se ha convertido en centro del debate sobre el exceso y los excesos de la publicidad exterior. Es significativo que a raíz de la noticia sobre la prohibición en Grenoble, un experto reclamara una "grenobilización" de las ciudades españolas, considerando a Madrid una ciudad "ejemplarmente castigada, durante décadas e in crescendo, por la publicidad urbana", en la que se imponía la necesidad de despejar su espacio urbano (Mosteiro, 2014). En este contexto, resulta más que pertinente estudiar los orígenes históricos del sector de la publicidad exterior en España a través del caso de Madrid, no solo porque esta ciudad es foco de los debates en torno a los excesos publicitarios en los espacios públicos, sino también porque, como se argumentará en este artículo, Madrid fue un buen ejemplo de la conformación de las ciudades modernas como espacios publicitarios privilegiados desde finales del siglo XIX.

Un proceso que tuvo lugar en el contexto del desarrollo y crecimiento económico del periodo, y de unas transformaciones sociales y culturales de gran magnitud y alcance, entre las que se sitúa la aparición de la publicidad moderna, una nueva herramienta comunicativa cuyos orígenes están intrínsecamente ligados al mundo urbano, transformado en el hábitat natural para los cada vez más sofisticados mensajes comerciales (Eguizábal Maza, 1998; Balandrón Pazos, 2007). En el caso de España, hay que considerar la aparición y consolidación durante el primer tercio del siglo XX de un vigoroso y avanzado sector publicitario, que se sostuvo sobre un pujante negocio, que movía en torno a cien millones de pesetas anuales en los años 30 (Prat Gaballí, 1934:25). El negocio de la publicidad se concentraba en los dos grandes núcleos urbanos del país, Madrid y Barcelona, donde se localizaban la mayor parte de los 
anunciantes y de los medios de comunicación que servían como canales publicitarios, y asimismo el mayor volumen de consumidores, dado el potencial demográfico de ambas ciudades.

Este trabajo se centra en uno de los sectores publicitarios menos atendido por los trabajos dedicados al estudio de la publicidad en España en ese periodo, el de la publicidad exterior. Si exceptuamos la abundante obra dedicada a la edad de oro del cartelismo, son escasas las investigaciones que hasta la fecha se han preocupado de establecer desde una perspectiva histórica, el impacto social de este sector de la publicidad. El artículo trata trata de arrojar luz sobre ese terreno, y para ello se basa en el análisis de documentación procedente del Archivo de Villa de Madrid (AVM), donde se han localizado decenas de expedientes inéditos que contienen solicitudes para realizar publicidad en las vías públicas de Madrid entre 1900 y 1936 . El número y variedad de estos expedientes confirman, por una parte, la consolidación del sector en ese periodo, y por otra, la creciente presión publicitaria que soportaba la ciudad, y que aquí es valorada como un rasgo de la modernización que la capital de España experimentó a lo largo del primer tercio del siglo XX (Rodríguez Martín, 2015).

\section{1 'El negocio del anuncio': la publicidad exterior en Madrid durante el primer tercio del siglo XX}

Como todavía ocurre en nuestros días, la forma más común y extendida de publicidad exterior en Madrid durante el primer tercio del siglo XX -también la más antigua- eran los rótulos que utilizaban los establecimientos comerciales para dar a conocer su existencia y diferenciarse de la competencia (figuras 1-2). En la época este tipo de anuncios se denominaban 'muestras', y su colocación estaba regulada en las ordenanzas municipales, que establecían las normas respecto a su tamaño y ubicación. El Ayuntamiento fijaba además las tasas que debían satisfacer los comerciantes por lucir estos reclamos, que se fabricaban con los materiales más diversos, aunque los más comunes eran la madera pintada y las placas y letras metálicas. En ellos se leía generalmente el nombre del comercio, que también de forma frecuente se acompañaba de algún tipo de decoración o de iluminación.

Con el tiempo, estos reclamos se fueron haciendo cada vez más sofisticados, para hacer más atractivos los establecimientos, que buscaban diferenciarse de la competencia en una ciudad cuyo sector comercial era abultadísimo, en consonancia 
con el tamaño de la población a la que abastecía. En los años 20 se generalizó la práctica de instalar en las fachadas de los comercios anuncios de productos de marca, indicando al público que allí podían adquirirse los artículos en cuestión. Este sistema publicitario que promocionaba la venta de productos estandarizados estaba orientado a fidelizar a los consumidores, al crear entre ellos el hábito de solicitar determinadas marcas cuando acudían a los establecimientos. En el Ayuntamiento se presentaban solicitudes como la de Eduardo Zato y García, para instalar en su tienda de Pi y Margall 11, "una farola anuncio" promocionando los "Productos Kodak"

En el sector comercial madrileño de la época era habitual colocar reclamos temporales para anunciar al público determinadas ventas o promociones, utilizando lonas, telas y hules pintados. Un ejemplo es la inscripción colocada en 1929 en la fachada de los grandes almacenes Madrid-París con el texto "10 DÍAS-CUATRO PRECIOS-1-2-3-5 Pts." que tenía una longitud de $22 \mathrm{~m}$, o la instalada en la fachada de los Almacenes de la Puerta del Sol para anunciar la 'Quincena de Blanco y Color del 31 de Enero al 16 de Febrero' en 1931. También la colocada en enero de aquel mismo año por los Almacenes Quirós para anunciar sus rebajas estacionales con el texto "Liquidación restos de invierno". ${ }^{5}$ Aunque su colocación fuera temporal, estaban igualmente obligados a dar de alta estos anuncios en el Ayuntamiento, pagando el correspondiente impuesto. Así lo hizo por ejemplo Ramón Gistán, cuando en 1930 instaló en la portada de su Bar Refectorio de la calle Atocha, una tela de 20x0.80 m anunciando que su establecimiento ofrecía "Donout americano". ${ }^{6}$
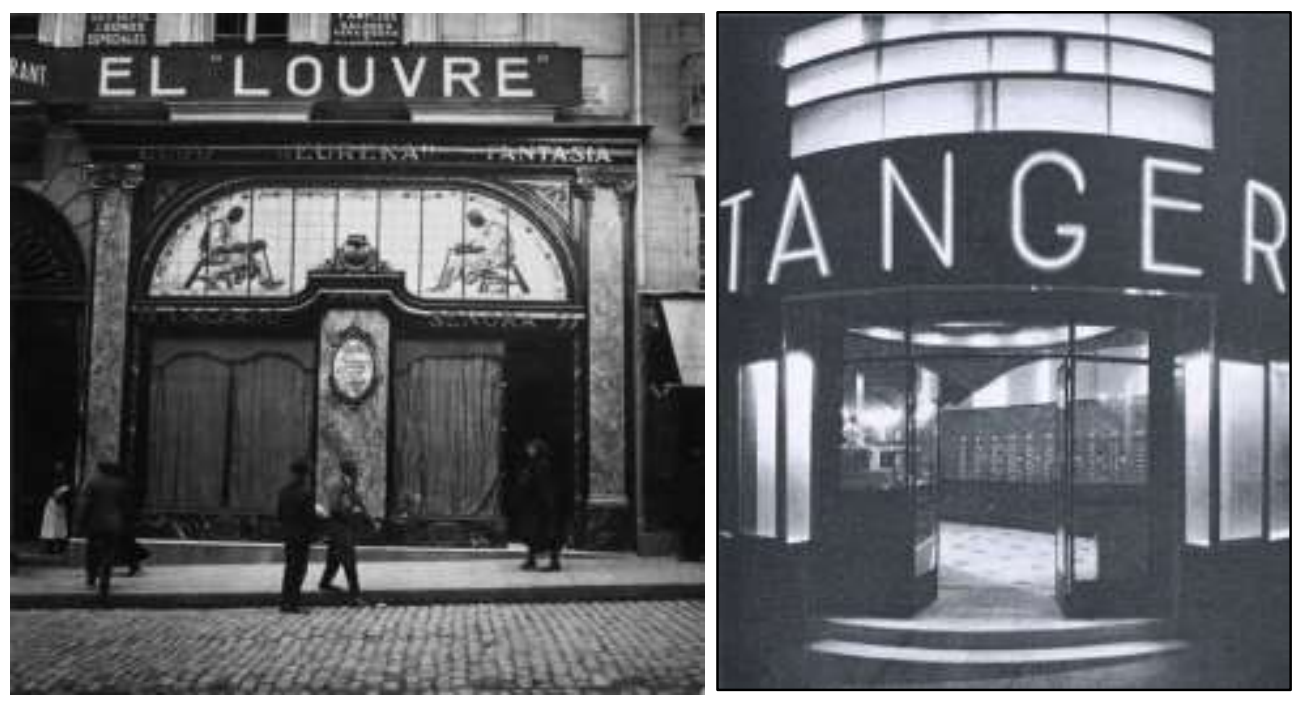

Figuras 1 y 2. Rótulos comerciales en Madrid, años 30 (Fuente: Museo de Historia de Madrid, Inv. 2002/7/73 y Nuevas Formas, no 4, 1935, digitalizadas y disponibles en www.memoriademadrid.org)

\footnotetext{
${ }^{4}$ AVM, Secretaría, expediente. 26-401-147.

${ }^{5}$ AVM, Secretaría, legajo. 26-402.

${ }^{6} \mathrm{AVM}$, Secretaría, legajo. 27-229.
} 
Era muy frecuente sin embargo que los comerciantes, especialmente los dueños de negocios modestos, no solicitaran en estos casos la autorización necesaria para instalar estos anuncios temporales, para ahorrarse el pago del correspondiente arbitrio. Corrían así el riesgo de ser denunciados por los inspectores municipales, recibiendo la correspondiente sanción en forma de multa, algo que sucedía de forma muy habitual, a juzgar por las numerosas denuncias cursadas que se han conservado en el Archivo de Villa de Madrid. Un ejemplo de estas sanciones es la impuesta en 1930 a Nicanor Rodríguez, propietario de una droguería, por tener colocada en la fachada de su establecimiento una gran tela sin declarar con la que anunciaba "Regalos los jueves". ${ }^{7}$

Los inspectores municipales mostraban gran diligencia a la hora de multar por anuncios sin licencia, fueran o no temporales, como revelan los expedientes consultados. Aunque su trabajo fuera la vigilancia en el cumplimiento de la normativa municipal, el celo con el que cursaban estas denuncias revela también un claro interés recaudatorio, confirmado por otras actuaciones. Por ejemplo, la aprobación por el Ayuntamiento de Madrid en 1924 de un arbitrio sobre los rótulos y anuncios de los comercios de la ciudad que emplearan voces en leguas extranjeras, medida que se enmarcaba en el impulso al nacionalismo español de la dictadura de Primo de Rivera, pero que podía suponer hasta 5 pesetas por palabra y mes en el pago del impuesto por anuncios en la vía pública. Aunque la norma se justificó como un intento de atajar "[el] desmedido abuso, cada día creciente, del empleo de palabras exóticas en la vida comercial madrileña", ${ }^{8}$ es muy significativo que la propuesta hubiera partido de la comisión de Hacienda del Ayuntamiento.

Durante las últimas décadas del siglo XIX, y de forma similar a lo ocurrido en otras grandes capitales europeas (Wischermann y Shore, 2000), se instaló en Madrid mobiliario urbano destinado específicamente a la fijación de carteles de publicidad, como las columnas y las carteleras de espectáculos, lo que no hizo sin embargo que esas piezas publicitarias desaparecieran de los muros de los edificios, donde hasta entonces se fijaban, sino que multiplicó su presencia en el paisaje urbano. El cartel había adquirido una extraordinaria difusión en todo el mundo occidental desde mediados del siglo XIX, razón por la cual está considerado como el primer medio publicitario dirigido a las masas (Checa Godoy, 2015). El desarrollo de la litografía, que permitió realizarlos de forma más barata y con mayor calidad, la implicación de artistas plásticos como Toulouse Lautrec, Jules Chéret, Alphonse Mucha, o Ramón Casas en España, y la celebración de concursos y exposiciones, hicieron que el cartel comercial alcanzara un gran prestigio, además de convertirse en una herramienta de democratización del arte, una cuestión subrayada por los contemporáneos. En el artículo "La evolución artística del anuncio" publicado en La Esfera en 1917, el

\footnotetext{
${ }^{7}$ AVM, Secretaría, expediente. 27-94-1.

${ }^{8}$ AVM, Secretaría, expediente 22-134-131.
} 
periodista y crítico de arte Silvio Lago $^{9}$ defendía la publicidad comercial moderna como "elemento de nivelación y progreso social" (Lago, 1917). Resaltaba el escritor el trabajo de ilustradores como Penagos y Bartolozzi para la Perfumería Floralia, una firma que otorgaba libertad creativa a los artistas a quienes contrataba para crear sus anuncios, y que de este modo habían producido notables ejemplos, por lo que bien podía adjudicarse el mérito de haber contribuido decididamente a elevar el arte del cartelismo en España. De tal modo, concluía, que la publicidad servía también a la educación estética de las muchedumbres. ${ }^{10}$ Los publicitarios españoles de la época que teorizaron sobre la publicidad, divulgaron esta misma idea en sus escritos, con el objeto de exaltar su contribución al progreso social y material del país (Prat Gaballí, 1917; Borí y Gardó, 1936).

La mayoría de los carteles que se adherían a las columnas anunciadoras o a las paredes de los edificios en Madrid no habían sido realizados por artistas de renombre, pero sí algunos de ellos, exhibiéndose también otros que sin llevar la firma de reconocidos ilustradores tenían una gran calidad desde el punto de vista estético. En 1925, por ejemplo, la empresa Fiat Hispania llenó de un rojo llameante la ciudad colocando 100 carteles diseñados por Plinio Codognato, verdaderamente deslumbrantes, para promocionar su modelo de automóvil Fiat 509. ${ }^{11}$ Sin embargo, en el primer tercio del siglo XX, los anunciantes y publicitarios españoles estaban más interesados en la efectividad de los mensajes comerciales que en el nivel artístico de los carteles, o al menos en la necesidad de supeditar el segundo a la primera (Prat Gaballí, 1933). Así lo afirmaba en 1926 José Gardó, exponiendo que el dibujante debería estar siempre sometido a las directrices del director de la campaña publicitaria, porque "el cartel esencialmente artístico sin base publicitaria no da el rendimiento del que se ha concebido de conformidad con la técnica del anuncio" (Gardó, 1921: 5-6). En 1928, otro técnico en publicidad español, José M. de Colubí, sostenía rotundo que "La Publicidad no debe doblegarse a la exigencia del Arte. Es el Arte que debe someterse a las leyes de la Publicidad" (De Colubí, 1928: 64).

\footnotetext{
${ }^{9}$ Pseudónimo de José Francés y Sánchez-Heredero

${ }^{10}$ La Esfera, 6-01-1917.

${ }^{11}$ AVM. Secretaría, legajo. 23-468.
} 


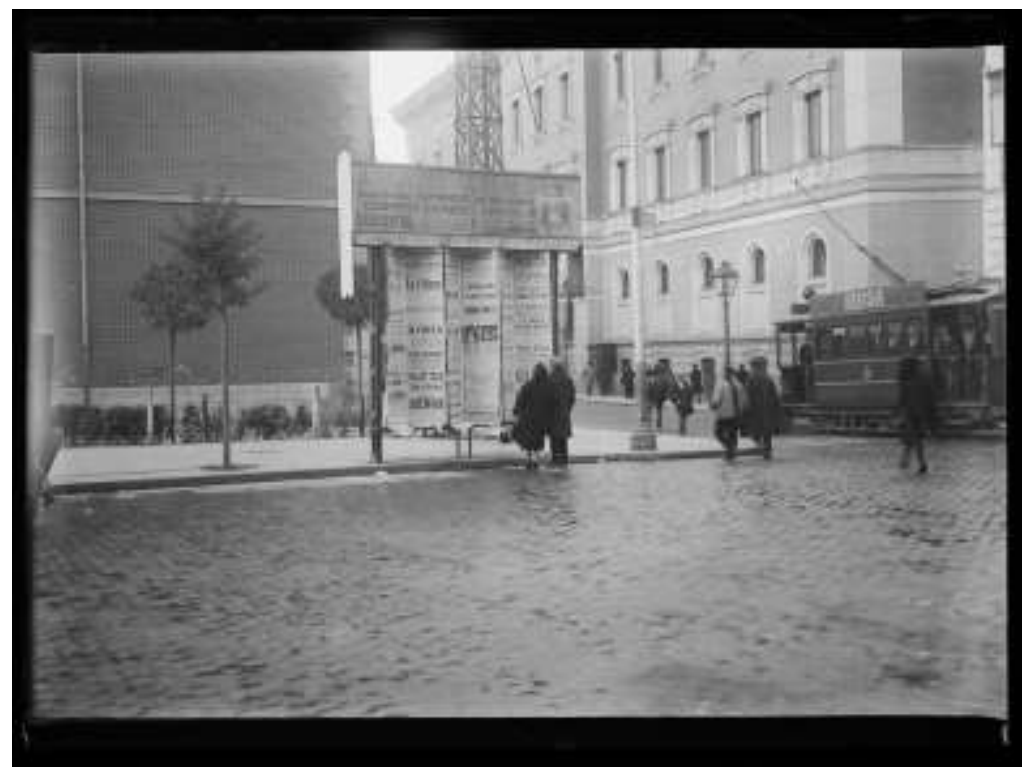

Figura 3. Cartelera de espectáculos en una calle de Madrid, circa 1927. (Fuente: Hemeroteca Municipal de Madrid. Núm. de inventario: HMM136. Fotografía digitalizada y disponible en www.memoriademadrid.org)

En Madrid las carteleras de espectáculos eran propiedad del municipio y se consideraban un servicio público, estando reservadas para el pegado de carteles que anunciaban las diversiones públicas (figura 3). Pero el Ayuntamiento no las explotaba directamente, sino que las arrendaba a un contratista que funcionaba como intermediario entre los anunciantes y el Consistorio, a quien satisfacía un canon anual. Los contratos se firmaban por 10 años, y los adjudicatarios estaban obligados al mantenimiento y reparación de los aparatos. Al comenzar el siglo XX, había 20 carteleras situadas en las principales calles y plazas de la capital (Ayuntamiento de Madrid, 1905). En 1923, el contrato firmado con Juan Pérez Salazar, le autorizó a cobrar 30 céntimos por anuncio fijado, a cambio de un pago anual al Ayuntamiento de 20.000 pesetas. Pero siendo tan elevado el número de teatros y cinematógrafos en la ciudad, el negocio estaba asegurado. ${ }^{12}$ Se estableció además un recargo de un $25 \%$ para los anuncios instalados en las carteleras de la Puerta del Sol y calles de Alcalá y Gran Vía, por ser las más codiciadas de la ciudad para publicitarse.

Dispersas por la ciudad, pero de forma más profusa por el distrito Centro, estaban las denominadas columnas y farolas anunciadoras, que se fabricaban con diversos materiales y adoptaban distintas formas, más variadas y creativas con el paso de los años. Estos soportes se instalaban tanto a instancias de comerciantes que querían promocionar sus negocios, como de pequeños industriales y de agencias de publicidad que las explotaban alquilándolas a los anunciantes. Una variedad eran las farolas anunciadoras luminosas, que incorporaban dispositivos, generalmente bombillas, para hacerlas más llamativas para el público. Uno de los soportes más utilizados en la

\footnotetext{
${ }^{12}$ AVM, Secretaría, expediente 26-443-1.
} 
publicidad exterior en Madrid eran las vallas, pues en una ciudad sumergida en una febril actividad constructora, en la que se acometieron grandes reformas urbanas, eran un elemento que proliferaba. Pueden considerarse una modalidad de las carteleras, pues servían en su mayoría para fijar carteles -aunque también podían pintarse directamente sobre ellas los anuncios -y estaban igualmente sometidas a regulación y al pago de tasas.

La normativa establecía que la explotación publicitaria de las vallas situadas en terrenos de propiedad municipal se realizaba mediante subasta pública. El aprovechamiento de este tipo de soportes generaba buenos beneficios, pues el Consistorio de Madrid recibía instancias de particulares y agencias solicitando su alquiler ofreciendo a cambio considerables sumas de dinero. ${ }^{13}$ Aunque el Ayuntamiento rechazaba estas instancias por estar obligado a sacar a subasta el alquiler de las vallas que fueran a ser objeto de explotación publicitaria, no siempre lo hacía. En 1910, por ejemplo, estando en construcción unos evacuatorios subterráneos en la Puerta del Sol, se autorizó directamente a Manuel Pérez Aguirre a explotar con anuncios la valla que servía de cerramiento a la obra, a cambio del pago de 250 pesetas mensuales, basándose en que era una autorización temporal. ${ }^{14}$

Las vallas de propiedad privada eran cedidas por sus propietarios a cambio de una cantidad de dinero a las agencias de publicidad. En 1930, en el solar dejado por el derribo del Teatro Apolo en la calle de Alcalá, y mientras se construía el nuevo edificio del Banco de Vizcaya, la Compañía Española de Publicidad, explotó un inmenso mural que según el gerente de la agencia, estaba dotado "de características a tono con las modernas orientaciones de publicidad empleadas en las grandes capitales" (figura 4). ${ }^{15}$ Para aumentar su impacto y que pudiera ser vista tanto de día como de noche, la agencia solicitó la instalación de un soporte con seis reflectores eléctricos para iluminarla.

\footnotetext{
${ }^{13}$ AVM, Secretaría, expediente 26-473-14.

${ }^{14}$ AVM, Secretaría, legajo 20-448.

${ }^{15}$ AVM. Secretaría, expediente 26-133-2.
} 




Figura 4. Valla publicitaria en la calle Alcalá de Madrid, 1930. (Fuente: AVM, Secretaría, expediente 26133-2)

La aplicación de la energía eléctrica permitió a la publicidad exterior dar un salto cualitativo. Los anuncios en las calles podían así ser vistos sin dificultad tanto de día como de noche, gracias a la aplicación de la iluminación artificial por medio de electricidad. En un primer momento se emplearon bombillas incandescentes, y en los años 30 se generalizó el uso de los tubos fluorescentes con gas neón, que añadieron color a la luminiscencia. La popularidad que la publicidad luminosa adquirió en las grandes ciudades estimuló las innovaciones, y los anuncios fueron haciéndose cada vez más grandes y más elaborados, incorporando distintos efectos para aumentar su visualidad. En las grandes metrópolis occidentales, como Nueva York y París, se colocaron los reclamos luminosos más espectaculares, algunos de proporciones gigantescas -como el instalado por Citroën en la Torre Eiffel en los años 20- que pasaron a ser una más de las atracciones que ofrecían. La publicidad luminosa fue muy bien recibida por los contemporáneos, no solo porque se la asociaba con la modernización y progreso de las ciudades, sino también porque contribuía a aumentar la iluminación nocturna en las urbes. Por esta razón, el Ayuntamiento de Madrid aprobó en 1916 una norma para que estos anuncios pagaran una cuota reducida respecto a la que satisfacían los no luminosos, justificándose en que:

de día no forman el verdadero reclamo y de noche hacen sólo 3 ó 4 horas a lo sumo, siendo además infinitamente más costosa su instalación y 
entretenimientos aparte de que favorecen el ornato público dando a las vías públicas una visualidad y aspecto que todos son en alabar ${ }^{16}$.

Los establecimientos comerciales madrileños comenzaron a colocar farolas y otros reclamos luminosos para captar la atención de los viandantes, y algunos anunciantes recurrieron a la publicidad luminosa, emplazando inmensos anuncios en las fachadas o en las azoteas de los edificios, a pesar de su mayor coste de fabricación, instalación y mantenimiento. En 1913, el fabricante A.E.G. fue uno de los primeros en instalar en la capital de España un anuncio luminoso de enormes proporciones. Publicitaba su lámpara Egmar, estaba emplazado sobre un edificio en la Puerta del Sol, tenía $6 \mathrm{~m}$ de altura y la forma de una bombilla. ${ }^{17}$ El diario El Imparcial recogió en una nota que el anuncio producía un "efecto mágico" y contribuía a que, en cuestión de grandes anuncios luminosos, Madrid se fuera pareciendo cada vez más al resto de capitales europeas. ${ }^{18}$ Antes de finalizar la primera década del siglo $\mathrm{XX}$, se instalaron otros luminosos de gran tamaño en la zona central de Madrid, como el que publicitaba las bodegas José Soto. Tenía un tamaño de $75 \mathrm{~m}^{2}$, y fue construido e instalado en 1919 por la empresa madrileña Luminosos Gironés, sobre el tejado de un edificio en la Puerta del Sol, contribuyendo al alumbrado de la céntrica plaza gracias a sus 10.000 bujías. ${ }^{19}$

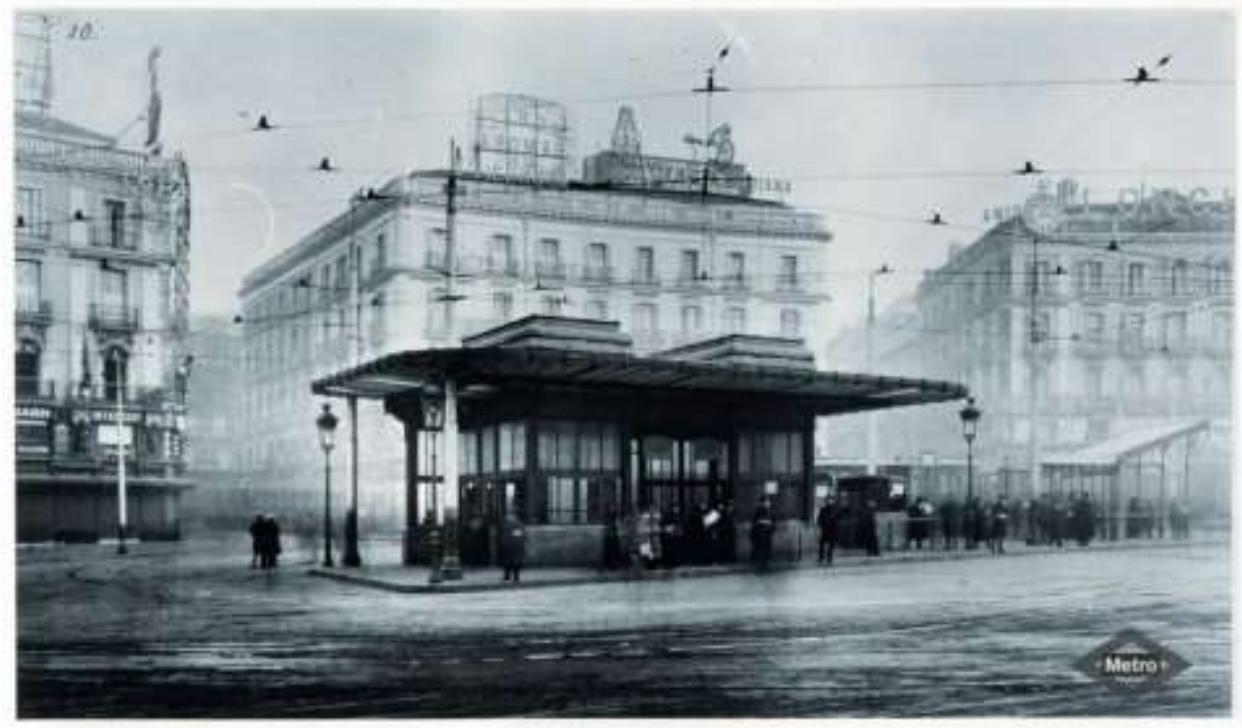

Figura 5. Anuncios luminosos sobre edificios de la Puerta del Sol de Madrid, 1920. (Fuente: Archivo fotográfico de Metro de Madrid. Sig.: MetroMadrid_2761. Fotografía digitalizada y disponible en www.memoriademadrid.org)

\footnotetext{
${ }^{16}$ AVM, Secretaría, legajo 20-363-11.

${ }^{17}$ AVM, Secretaría, legajo 18-272.

${ }^{18}$ El Imparcial, 10-11-1913.

${ }^{19}$ ABC, 22-11-1919.
} 
La Puerta del Sol se convirtió en el lugar preferido para colocar los reclamos luminosos más espectaculares (figura 5). Una relación de anuncios de esta clase instalados en el distrito Centro elaborada por el Ayuntamiento en 1916 reveló que la mayoría de ellos estaban ubicados en la Puerta del Sol o en calles adyacentes a la plaza: un total de 17 anuncios que abonaban una tarifa anual de entre 60 y 330 pesetas según su tamaño. ${ }^{20}$ La concentración de esta clase de anuncios en la conocida plaza la convirtieron en el espacio publicitario privilegiado de la ciudad. La Puerta del Sol era el punto de mayor intensidad circulatoria, por lo que su conformación como eje publicitario predilecto no resulta sorprendente. El primer estudio sobre volumen y desplazamiento de transeúntes realizado en Madrid en 1925, estableció un promedio de 48.000 peatones por hora en un día corriente para la Puerta del Sol y sus calles afluentes (Abarca, 1926:5).

En la década de los 20 se popularizaron en la ciudad los rótulos de neón, que brillaban en la oscuridad con más intensidad y en distintos colores, y que modificaron radicalmente el aspecto que ofrecían sus vías céntricas en las horas nocturnas. Los grandes almacenes y los cinematógrafos situados en el distrito Centro, fueron los primeros en instalar esta nueva tecnología. En 1929 el Cine Callao, en la plaza del mismo nombre, colocó sobre su fachada principal un enorme anuncio de $200 \mathrm{~m}^{2}$ a base de los característicos tubos luminosos rojos. ${ }^{21}$ Ya en 1935 se emplazó en la azotea de un edificio de la Puerta del Sol uno de los más grandes hasta entonces, instalado por las bodegas González Byass para celebrar su centenario. Consistía en una enorme estructura de 70 toneladas de peso formada por las letras del nombre de la empresa bodeguera. 22 Este anuncio -transformado en los años 50 por el de su marca de vinos Tío Pepe-, fue declarado patrimonio histórico-cultural de la ciudad en 2009 por el Ayuntamiento, y aun hoy permanece en la Puerta del Sol, por lo que podemos considerarlo una de las huellas más vistosas que la publicidad $-\mathrm{y}$ por tanto la nueva cultura del consumo -imprimió en el paisaje urbano de Madrid. La proliferación de anuncios luminosos, con o sin gas neón, se tradujo en el crecimiento del número de industrias que en Madrid se dedicaban su fabricación e instalación. Empresas como Tuboluz, Luminosos Triunfo, Harriluz, Electrodo-Neón y Luminosos Pajares, etc., etc., lo que hace pensar también que el coste de los mismos se fue abaratando, haciéndose accesible para anunciantes y establecimientos más modestos. ${ }^{23}$

También la publicidad exterior móvil o circulante era muy abundante y habitual durante el primer tercio del siglo XX. Los transportes urbanos de la época, tanto el

\footnotetext{
${ }^{20}$ AVM. Secretaría, expediente 20-363-11.

${ }^{21}$ AVM, Secretaría, legajo 15-26*.

22 Datos proporcionados por el gabinete de prensa de González Byass.

${ }^{23}$ De las 48 solicitudes al Ayuntamiento de Madrid para instalar anuncios luminosos en la ciudad en el año 1932, 8 correspondieron a anuncios de neón. AVM, Secretaría, legajo 27-230.
} 
Metro -en sus estaciones y en sus trenes - como los tranvías y los autobuses, llevaban instalada publicidad. Solamente los taxis tenían prohibida la exhibición de anuncios. El tranvía era un vehículo publicitario muy atractivo para los anunciantes, por su poder de impactar casi de forma permanente en prácticamente toda la ciudad, dada la extensión de la red tranviaria en esos momentos. La principal compañía de transportes urbanos de la época en Madrid, la Sociedad Madrileña de Tranvías, contaba a comienzos de los años 30 con 525 coches en circulación, sobre los que se montaban los anuncios publicitarios en forma de tableros, de chapas y de transparentes ${ }^{24}$. En el caso del ferrocarril subterráneo, la publicidad, según muestran las fotografías de la época, se colocaba tanto en las estaciones como dentro de los vagones destinados a los viajeros. También los vehículos privados, particularmente los automóviles, se utilizaban como soportes publicitarios, pagando la correspondiente cuota al Ayuntamiento por los derechos de exhibición de anuncios en la vía pública.

La proliferación de las distintas formas de publicidad exterior a lo largo del primer tercio del siglo XX, denota la creciente presión publicitaria que soportaba el espacio público en Madrid en ese periodo. A pesar de ello, el Ayuntamiento de la ciudad seguía recibiendo propuestas, la mayoría proponiendo la explotación y aprovechamiento publicitario de mobiliario urbano existente, o bien la instalación de nuevos elementos. Son muchas, por ejemplo, las ofertas de industriales para instalar gratuitamente bancos y sillas en las plazas y paseos públicos (figura 6). ${ }^{25}$ Eran elementos que se prestaban bien como soportes anunciadores, y de los que la ciudad carecía en número suficiente para el tamaño de su población.

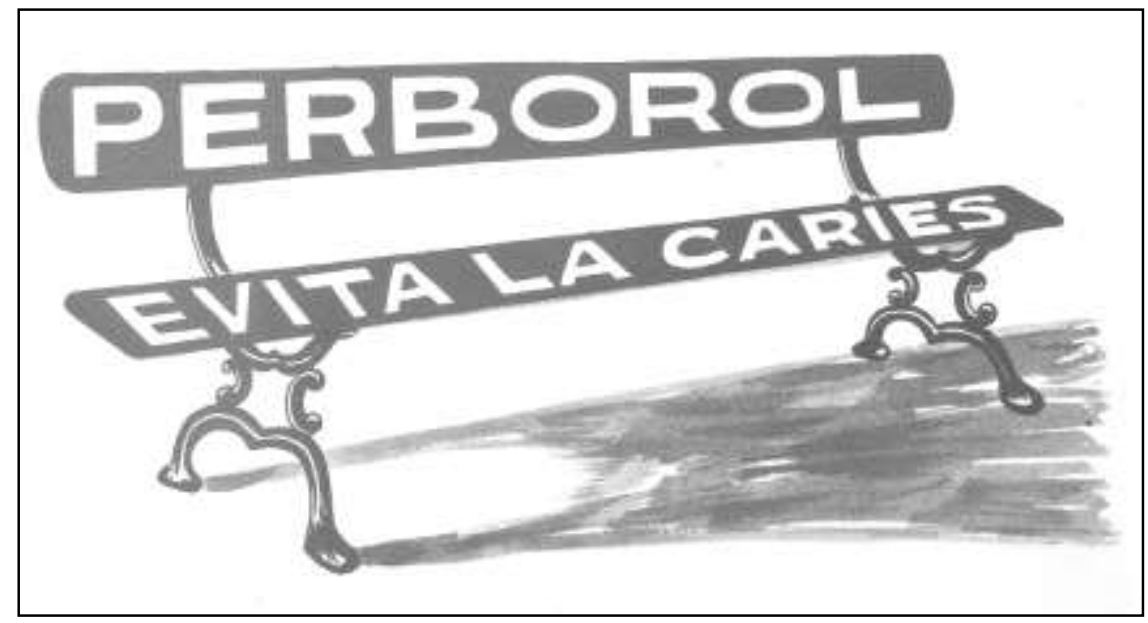

Figura 6. Proyecto de banco anunciador, años 20. (Fuente: AVM, Secretaría, expediente 23-482-43)

Pero estas propuestas no prosperaban porque el Ayuntamiento era reticente a otorgar este tipo de concesiones, que como contrapartida a la gratuidad del ofrecimiento

${ }^{24}$ AVM, Secretaría, expediente 31-30-33.

${ }^{25}$ AVM, Secretaría, expedientes $18-466-92 ; 26-443-4 ; 22-92-68$ y 22-482-43. 
exigían la exención en el pago de tributos por anuncios en la vía pública. A finales de 1933, sin embargo, un concejal propuso autorizar anuncios en las sillas y sillones de los paseos públicos de la ciudad, y el Ayuntamiento proyectó entonces un concurso público para otorgar la explotación de este sistema publicitario. ${ }^{26}$ Dos años después, se adjudicó por contrato público la instalación de las primeras papeleras propiamente dichas que tuvo Madrid, y que llevaban incorporado un poste para la fijación de anuncios. ${ }^{27}$ Su colocación corrió a cargo de un concesionario, y la profusión con que fueron diseminadas por algunas calles -se entiende que para conseguir la mayor recaudación posible por inserción de anuncios-creó gran malestar entre el vecindario y algunos concejales, que fue aireado por la prensa, que llegó a denunciar: "Es que no se piensa, al conceder la autorización, en la distancia que hay entre un servicio público y un negocio privado". 28

El resto del mobiliario urbano también sufría la presión publicitaria. Las farolas del alumbrado público, las columnas y postes de la red tranviaria y telefónica e incluso las placas indicadoras del nombre de las calles (figura 7), fueron objeto de numerosas ofertas para colocar en ellas publicidad, siempre con exigencias de exclusividad y por un largo periodo de tiempo, a cambio del pago de una determinada cantidad al municipio. ${ }^{29}$ En ocasiones las proposiciones ofrecían la instalación de nuevos enseres y elementos en las vías públicas. Entre las localizadas en el Archivo de Villa de Madrid están las básculas para pesar personas que exhibían anuncios luminosos"30, butacas para limpiar el calzado con publicidad en el respaldo, un denominado "Faro anunciador mural", ${ }^{31}$ así como distintas modalidades de semáforos para regular el tráfico que además de las advertencias luminosas para vehículos y peatones podían mostrar 0 proyectar anuncios sobre edificios. ${ }^{32}$

\footnotetext{
${ }^{26}$ El Sol, 20-12-1933.

${ }^{27}$ La Libertad, 20-07-1934.

${ }^{28}$ Luz, 28-07-1934.

${ }^{29}$ AVM, Secretaría, expediente 29-61-35; AVM, Secretaría, expediente 29-61-35.

${ }^{30}$ Boletín Oficial de la Provincia de Madrid, 6-03-1930.

${ }^{31}$ AVM, Secretaría, expediente 25-290-2

${ }^{32}$ AVM, Secretaría, expediente 27-229-87.
} 


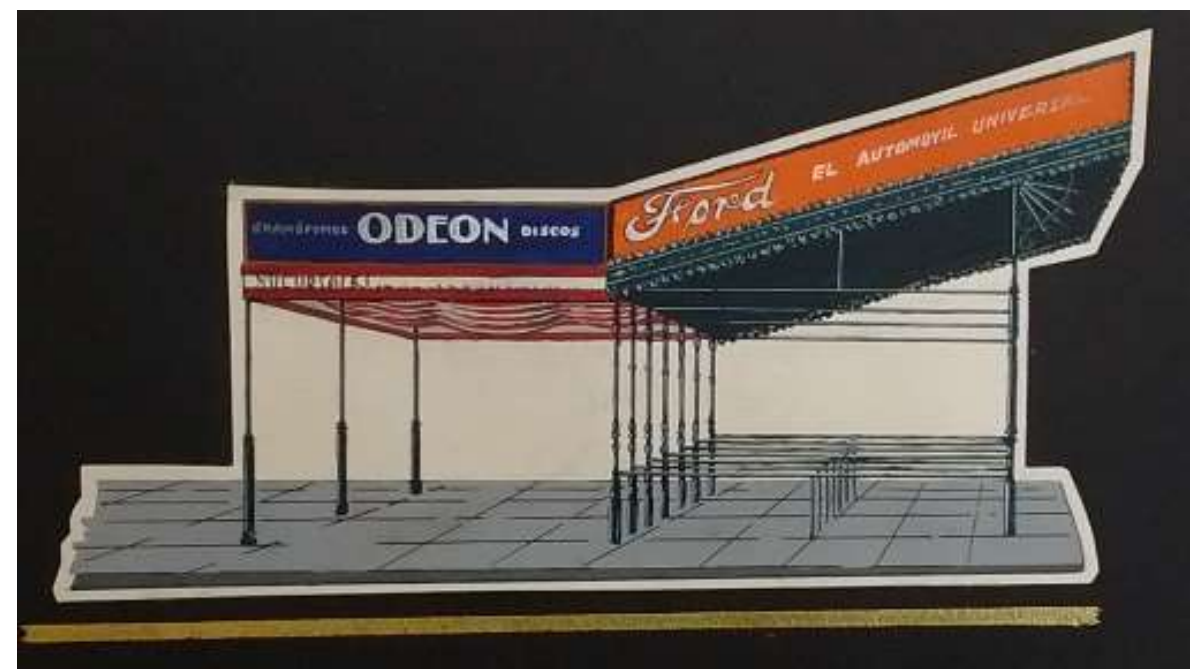

Figura 7. Propuesta de explotación publicitaria de las marquesinas del tranvía. (Fuente: AVM, Secretaría, expediente 23-114-52)

Las nuevas tecnologías contribuyeron a que surgieran nuevas propuestas y modalidades en el sector de la publicidad exterior. En 1910, la sociedad "Anuncios Hablados Gutiérrez Sanz", domiciliada en la calle Quevedo, 8 y 10, consiguió licencia del Ayuntamiento para instalar "13 aparatos anunciadores hablados" en puntos céntricos de la ciudad. ${ }^{33}$ Pero la publicidad acústica no tuvo un largo recorrido en Madrid, y propuestas similares recibidas por el Ayuntamiento, que conllevaban la instalación de grandes aparatos amplificadores en la vía pública, fueron repetidamente denegadas por causar trastornos en la circulación y molestias al vecindario. ${ }^{34}$ Una de las propuestas más llamativas que pudieron contemplarse en Madrid fue la proyección de anuncios sobre edificios con ayuda con un aparato cinematográfico, que en 1927 llevó a cabo Publicidad Rex. El sistema consistía en proyectar películas publicitarias que se intercalaban con otras grabaciones cinematográficas sobre las lunas de un edificio en la Gran Vía, convirtiéndose en una atracción para los viandantes, que contemplaban admirados la novedad, formándose diariamente aglomeraciones que hicieron intervenir al Director municipal de Tráfico. ${ }^{35}$

Columnas anunciadoras, carteleras, vallas, anuncios luminosos, soportes móviles, etc., etc., fueron medios pródigamente empleados en Madrid por todo tipo de fabricantes y comerciantes para publicitarse durante el primer tercio del siglo $\mathrm{XX}^{36}$. Como en el resto

\footnotetext{
${ }^{33}$ AVM, Secretaría, expediente 18-460-11.

${ }^{34}$ AVM, Secretaría, expediente 29-364-84.

${ }^{35}$ AVM, Secretaría, expediente 27-177-3.

${ }^{36}$ La forma en la que se realizaban las solicitudes al Ayuntamiento de Madrid para hacer publicidad en las vías públicas, hace muy complicado detallar qué productos, marcas y servicios eran los más publicitados. Las solicitudes podían contener información al respecto o no, en función de si se utilizaba un formulario simple o de si se presentaba una memoria detallada sobre el anuncio, en el caso de que este requiera instalaciones que precisaran la supervisión de un arquitecto o ingeniero municipal, por ejemplo en el caso de anuncios luminosos de gran tamaño. Tanto en uno u otro caso, la solicitud podía
} 
de las grandes capitales europeas, los habitantes de Madrid se acostumbraron a convivir con el asalto constante de los reclamos publicitarios, que pasaron a formar parte de su experiencia cotidiana. Esta profusión de mensajes e imágenes comerciales, si bien fue aceptada por los contemporáneos como una manifestación más de la modernización de la ciudad, comenzó al mismo tiempo a granjearse críticas y surgieron protestas contra lo que algunos consideraban ya entonces una auténtica "invasión del anuncio".

\section{2 "La invasión de los bárbaros del anuncio"}

En 1933 el periodista Jacinto Miquelarena denunciaba en un artículo en el periódico $A B C$ el exceso de reclamos comerciales en las calles de Madrid:

Ya no hay bastante, por lo visto, con las vallas de todas las obras, con los telones de todos los teatros, con los tranvías, con el Metro, con los tejados y con las superficies para inscripciones neolíticas que se ofrecen al comercio de las medias y de las gafas a lo largo de la carretera de la Sierra [...] Hace falta pintarrajear más cosas. La mirada no sabe ya dónde puede encontrar una perspectiva de reposo (Miquelarena, 1933).

El texto continuaba retratando la ciudad como un gigantesco escenario publicitario, a merced y disposición de los comerciantes y anunciantes, dispuestos a utilizar todo espacio disponible en la urbe para promocionar sus negocios y productos. La denuncia del periodista no era, como puede suponerse, completamente desinteresada, puesto que el diario competía con otros medios y canales por los ingresos publicitarios. Pero al mismo tiempo revela la aparición de una nueva percepción sobre los anuncios comerciales, que eran comúnmente considerados por los contemporáneos como un símbolo de la modernidad y de la vitalidad comercial de la ciudad. Además del exceso de anuncios, el articulista se quejaba de la pésima factura de muchos de ellos, que alteraban negativamente la estética urbana, pues era "inútil gastarse millones en belleza pública si a continuación se deja que cualquiera pueda degradarla. Si se tolera que el primer inventor de un tinte para el cabello ponga allí su cabeza parlante" (Miquelarena, 1933).

En la misma línea, el escritor Xavier Cabello Lapiedra arremetía en 1932 desde el diario La Época contra el exceso de anuncios luminosos instalados en Madrid que 
destrozaban la belleza arquitectónica de sus edificios. Por culpa de estos anuncios, las calles céntricas se convertían durante las noches en un "torbellino de iluminación, una constante llamarada de artificiales fuegos", donde solo era posible apreciar:

combinaciones de anuncios luminosos que emboban y marean al transeúnte, quien no contemplará un detalle artístico de la bella arquitectura, pero se irá a su casa fatigado de llevar incrustados en su cerebro los colorines de multitud de luces que anuncian mil cosas en confusa competencia, de un comercio enfermo de propaganda (Cabello Lapiedra, 1932).

Horrorizado por lo que denominaba "estilo arquitectónico pirotécnico", que venía a ser la subordinación de la arquitectura "al imperio de la industria anunciante", Cabello Lapiedra preguntaba retóricamente a sus lectores "si el reclamo mercantil o industrial [tenía] derecho a matar un arte". Estas son algunas de las críticas que comenzaron a menudear en la prensa desde mediados de los años 20, contra lo que algunos consideraban un desmesurado número de anuncios en las vías públicas de Madrid, y contra la contaminación visual que provocaban. La publicidad exterior se había convertido en un elemento omnipresente y transformador del paisaje urbano de la capital de España, hasta el punto de que en los años 30 era ya objeto de debate público. Un debate que acabó llegando al Ayuntamiento madrileño, a quien correspondía su regulación. Ya desde los primeros años del siglo se habían tomado algunas medidas para atajar la saturación publicitaria urbana, aunque no hubiera alcanzado las proporciones que tenía en ciudades como París ${ }^{37}$. Porque el exceso de anuncios en las vías públicas no solo afectaba ya a la estética urbana, sino al propio funcionamiento de la ciudad, algo que se hizo patente en los intentos de la municipalidad para suprimir determinadas formas de publicidad exterior, como el reparto de folletos y octavillas en las calles entre los viandantes. Esta actividad era tan habitual en los primeros años del siglo XX que en 1910 el alcalde Francos Rodríguez tomó la decisión de prohibirla, por constituir:

un verdadero abuso [...] que sobre ser un elemento de anuncio ya de poco interés para el público, constituye una causa de suciedad de las calles, haciendo inútiles los esfuerzos de los encargados de la limpieza por la imposibilidad de recoger la multitud de papeles que constante y profusamente se reparten a los transeúntes. ${ }^{38}$

\footnotetext{
37 Tan pronto como en 1887 París aprobó la primera ley contra la fijación de carteles en edificios y monumentos históricos de la ciudad, a la que siguieron otras similares en 1906 y 1910 . En 1926 se prohibió la publicidad luminosa en un perímetro alrededor de la plaza del Arco del Triunfo. Conseil Municipal de Paris (1927): Proposition tendant à reglamenter la publicité lumineuse dans Paris para applications de la loi du juillet 1924 ... (Rapports et documents, $\mathrm{n}$ - 4).
}

${ }^{38}$ AVM, Secretaría, expediente 19-440-24. 
Aunque la norma no impidió que se siguiera practicando, hasta el punto de que en 1930 el Ayuntamiento volvió a acordar en un pleno municipal la prohibición de repartir prospectos en las calles porque las ensuciaban, haciendo necesario intensificar el servicio de limpiezas, "y aun así, siempre quedan residuos que desdicen del celo e interés de la Corporación municipal en conservar las vías públicas en las condiciones debidas de limpiezas". En 1914, ante la proliferación de columnas y farolas anunciadoras, el Ayuntamiento acordó no conceder más licencias de instalación. Las ordenanzas vigentes prohibían la instalación en las vías públicas de la ciudad de cualquier objeto que pudiera entorpecer o molestar el tránsito público. Pero esta norma era poco precisa y la autorización o denegación de una solicitud quedaban a la discrecionalidad del personal del negociado de Policía Urbana que se encargaba de gestionarlas, a veces solicitando informes a la sección de Vías Públicas del Ayuntamiento.

Desde los primeros años del siglo $X X$, sin embargo, el aumento de los problemas circulatorios en Madrid, y la creciente congestión viaria en las vías céntricas de la ciudad, llevaron al Ayuntamiento a aprobar repetidos acuerdos que recordaban la necesidad de desestimar todas las peticiones de esa naturaleza. Es lo que le sucedió, entre otros, a Guillermo Bernstein, quien en 1921 pretendía instalar en la plaza de Canalejas una "farola, anunciadora, luminosa, instantánea" de $5 \mathrm{~m}$, en la que se podían introducir hasta cuarenta anuncios. ${ }^{39}$ Sin embargo, a pesar de que los técnicos municipales abogaban por mantener un criterio restrictivo o directamente prohibitivo para este tipo de publicidad, no se aplicó de forma estricta. Un informe municipal de 1923 remite a la ambigüedad con la que se siguió trabajando en esta cuestión. Aunque se aboga en él por restringir todo lo posible la instalación de columnas anunciadoras, se afirma igualmente que "no se puede desconocer que es un sistema de anuncio empleado en todas las capitales europeas" y que podrían concederse las solicitudes siempre que se vigilase su aspecto estético y su ubicación. ${ }^{40}$

La instalación de anuncios luminosos, favorecida por el Ayuntamiento en los primeros momentos de su desarrollo por contribuir a la iluminación y decoración de las vías públicas, se vio gravada en un $50 \%$ en 1932. La medida provocó la protesta de los fabricantes de estos anuncios, así como de la Asociación Española de Luminotecnia, que propagaba los usos de la electricidad en España, que en una instancia a la alcaldía le recordó que el aspecto atractivo de una ciudad dependía en gran parte de los anuncios luminosos "razón por la cual en todas las Capitales europeas se propaga y favorece por la Municipalidad el empleo de esta clase de anuncios" ${ }^{41}$ El Ayuntamiento contestó que la medida trataba únicamente de corregir las desigualdades que existían

\footnotetext{
${ }^{39}$ AVM, Secretaría, expediente 21-288-139.

${ }^{40}$ AVM, Secretaría, expediente 22-92-79.

${ }^{41}$ AVM, Secretaría, expediente 27-66-54.
} 
en la tributación de los anuncios en la vía pública. La instalación y funcionamiento de los luminosos requería del trabajo de inspección y supervisión técnica de los ingenieros municipales, y de la colocación de andamios y escaleras que ocupaban las aceras. Era lógico, aducía, gravar más estos anuncios por las circunstancias que en ellos concurrían, añadiendo que la reforma iba también encaminada a corregir las diferencias del pago por tamaño de los neones. Un informe de la delegación municipal de Hacienda con motivo de la reclamación interpuesta por la empresa Neonray contra la ordenanza, refleja además el malestar del Consistorio por el escaso beneficio que obtenía de alquilar el espacio público para el beneficio exclusivo de los anunciantes:

Los anuncios en las calles de la capital de España, vienen siendo objeto de enorme especulación por parte de las infinitas empresas de publicidad que existen creadas, precisamente al amparo del insignificante tributo municipal que los grava. Cualquier periódico de Madrid obtiene de sus planas de anuncios muchísimo más rendimiento que el que logra el Ayuntamiento de la suya inmensa que abarca todo el perímetro de [...] $Y$ ello sin contar con que el anuncio de prensa tiene de vida escasamente las 24 horas que son las que vive la hoja impresa, mientras que la publicidad en las calles es de carácter permanente y mucho más llamativa y eficaz que aquella porque la leen, hasta sin querer los millares de almas que transcurren por la vía pública. ${ }^{42}$

También se trató de suprimir la publicidad móvil, por constituir un problema para la circulación viaria. El desfile de "hombres-anuncio", llevando cartelones u otros elementos de publicidad portátiles era tan habitual desde finales del siglo XIX, que aunque esta actividad no estuviera muy bien conceptuada por los contemporáneos (Enderiz, 1927), se aceptaba como parte del espectáculo urbano. Pero el desarrollo urbanístico, el crecimiento demográfico y la motorización de la ciudad durante el primer tercio del siglo XX pusieron sobre la mesa la necesidad de reglamentar estrictamente la circulación viaria. Y la mayoría de la publicidad móvil -con excepción de la que iba montada sobre vehículos- se había convertido en los años 20 en un obstáculo para la organización del tráfico urbano, produciendo disrupciones en el tránsito. En 1928 todas las solicitudes de anuncios portátiles recibidas por el Ayuntamiento fueron denegadas, tras recibir todas ellas el mismo informe negativo de la oficina del Tráfico Urbano:

no debe accederse a ello por entorpecer la circulación de peatones, ya que la exhibición de estos portátiles debe efectuarse en continua circulación, dando lugar a que la natural curiosidad de los peatones constituya incluso corrillos, lo

\footnotetext{
${ }^{42}$ AVM, Secretaría, expediente $20-452 *-61$.
} 
mismo que cuando los portadores de ellos se paran para descansar y si circulan por las calzadas igualmente dificultan el tránsito rodado. ${ }^{43}$

Entre quienes vieron rechazada su solicitud se encontraba Francisco Sempere, que pretendía anunciar el anís y coñac marca general Primo de Rivera mediante la circulación de dos hombres que portaban sendas figuras de madera de gran tamaño que reproducían las botellas de los licores. ${ }^{44} \mathrm{El}$ Ayuntamiento también denegaba las solicitudes de anunciantes que solicitaban lanzar octavillas desde el aire utilizando avionetas, en este caso, por ensuciar la vía pública. ${ }^{45}$

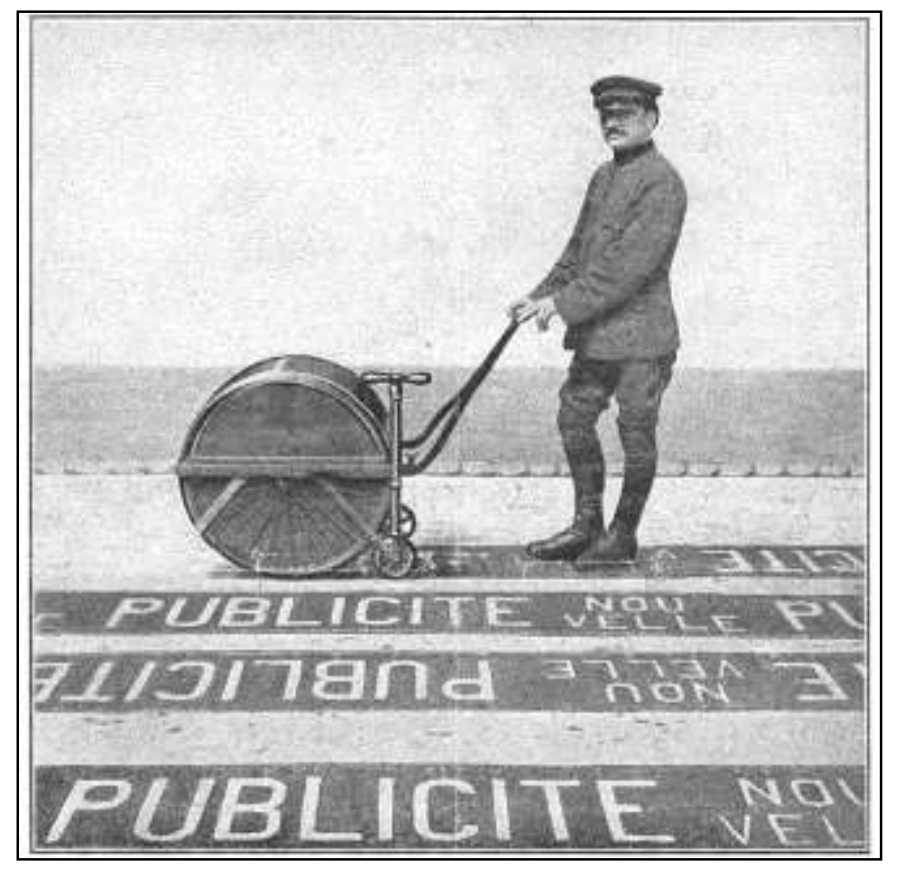

Figura 8. Publicidad circulante exhibida en Madrid, 1925. (Fuente: AVM, Secretaría, expediente 23-482-

41)

Aun siendo mayor el control que impuso el Ayuntamiento sobre la publicidad móvil en Madrid, esta forma de anunciarse no fue prohibida por completo, y en años posteriores se autorizaron algunas instancias para hacer este clase de propaganda comercial (figura 8). Los responsables de la regulación del tráfico en la ciudad fueron, junto a los técnicos de la sección de Vías Públicas del Ayuntamiento, los más críticos con lo que la municipalidad denominaba en los años 30 "el problema de los anuncios en la vía pública". Un problema que tenía varios aspectos. En primer lugar, la creciente presión publicitaria sobre los espacios públicos, con la multiplicación de propuestas de todo tipo, a cada cual más llamativa y elaborada, y la proliferación de anuncios en

\footnotetext{
${ }^{43}$ AVM, Secretaría, expediente 26-452-38.

${ }^{44}$ AVM, Secretaría, expediente 26-452-42.

${ }^{45}$ AVM, Secretaría, expediente 26-452-1.
} 
cantidades hasta entonces nunca vistas, de la que se hacían eco varios concejales en 1932:

De algún tiempo a esta parte se ha intensificado de modo extraordinario la colocación de carteles en la vía pública, llenándose por ello muchas fachadas y zócalos, columnas de alumbrado y de tranvías, kioscos, etc., de pasquines anunciadores, tanto de carácter político como de propaganda comercial. ${ }^{46}$

En segundo lugar, estaba la escasa y dispersa regulación de la publicidad urbana existente en esos años, que las propias autoridades locales no respetaban en algunas ocasiones, contravenían normas en vigor. Esto nos lleva a un tercer aspecto del problema, el de la recaudación por este concepto, que al fin y al cabo era una parte importante en el capítulo de ingresos municipales. Como se recogía en un informe de 1935, el Ayuntamiento:

[era] pródigo en otorgar concesiones de todas clases que las más de las veces al socaire de un menor gasto para la Corporación en unas ocasiones y de una fuente de ingresos en otras constituyen verdaderas zonas exentas de la policía municipal y a veces patente que se obtiene para el abuso e incumplimiento de la propia concesión. ${ }^{47}$

A mediados de los años 30, el Ayuntamiento, en vista de la saturación publicitaria que sufrían los espacios públicos de la ciudad, y de la necesidad de ordenar lo que recaudaba por los anuncios en las calles, y al mismo tiempo de atender las quejas y necesidades de los técnicos municipales que trabajan en las secciones de Tráfico y de Vías Públicas, decidió que había llegado el momento de gestionar más adecuadamente un sector que no dejaba de expandirse. Varios concejales habían propuesto en 1934 estudiar una posible "municipalización del anuncio", es decir, una gestión directa y sin intermediarios del negocio de la publicidad exterior en las vías públicas, como ya hacían otras municipalidades como la de París, donde desde mediados de los años 20, el Conseil Municipal de la ciudad estudió y aprobó distintas proposiciones sobre esta materia. ${ }^{48}$ En este contexto, comenzó a trabajar una comisión municipal que a lo largo del año 1935 fue recibiendo distintos informes sobre la cuestión. En uno de ellos se determinaba:

\footnotetext{
${ }^{46}$ AVM, Secretaría, expediente 29-61-35.

47 Ibídem

${ }^{48}$ Conseil Municipal de Paris (1922): Proposition tendant à l'organisation rationnelle d'un service municipal de la Publicité sur la Voie publique, présentée par M. Fernand-Laurent. Conseiller Municipal (Rapports et Documents, no 45); Conseil Municipal de Paris (1924): Proposition tendant à l'organisation d'une exploitation rationnelle de la publicité sur tous les emplacements dépendant du domaine municipal, déposée par M. Fernand-Laurent. Conseiller Municipal (Rapports et Documents, no 28); Conseil Municipal de Paris (1924): Rapport de M. Froment-Meurice sur différentes questions d'exploitation de la publicité (Rapports et Documents, $\mathrm{n}$ ㅇ 87).
} 
estimamos que el expediente actual debe cambiar completamente de rumbo, prescindiendo de estudios de iniciativas y de posibles adjudicatarios para pensar seriamente en impedir de manera absoluta la colación de nuevos obstáculos en la vía pública y supresión paulatina de los existentes, con lo cual iremos por un camino que nos conduzca a resultados completamente distintos de los obtenidos hasta ahora por el Ayuntamiento. ${ }^{49}$

Se nombró entonces una ponencia para proceder a un estudio completo de la reglamentación de anuncios en la vía pública. Para el Consistorio había llegado la hora de regular y organizar la publicidad en la ciudad de forma más firme y homogénea que hasta entonces. Pero estos propósitos fueron abortados por el comienzo de la Guerra Civil española. El expediente que contiene los trabajos de la comisión municipal se cerró el día 21 de diciembre de 1936 con un lacónico: "La Comisión teniendo en cuenta las actuales circunstancias se permite proponer a V.E. se dé por concluso el presente expediente referente a la municipalización de anuncios". ${ }^{50}$ La ciudad de Madrid sufría el terrible asedio al que se vio sometida hasta el final del conflicto bélico, y el estudio de la regulación de la publicidad exterior por la municipalidad quedó, como la mayor parte de asuntos, relegado por completo en tan anormal situación.

\section{Conclusiones}

Durante el primer tercio del siglo XX la publicidad exterior se convirtió en un elemento consustancial al paisaje urbano de Madrid. Como se ha detallado en este artículo, a lo largo del periodo se asistió al crecimiento exponencial de toda clase de anuncios en distintas formas, soportes, materiales y tamaños, para ser exhibidos en las vías públicas de la ciudad, expuestos permanentemente a la mirada de los viandantes. Fue un proceso similar al experimentado por otras grandes capitales europeas, algunas de las cuales, París por ejemplo, habían comenzado a soportar una gran presión publicitaria sobre los espacios públicos ya en las últimas décadas del siglo XIX.

Los contemporáneos respondieron a esta realidad de forma ambivalente. Por una parte, y de forma similar a lo que sucedió en otras metrópolis occidentales, la profusión de anuncios en Madrid, ya fueran estáticos, móviles, luminosos, acústicos, etc., fue acogida como un símbolo de la modernización de la ciudad en general, y de su

\footnotetext{
${ }^{49}$ AVM, Secretaría, expediente 29-61-35.

${ }^{50}$ AVM, Secretaría, Expediente 29-61-35.
} 
vitalidad comercial e industrial en particular. Por otra, se debatía públicamente sobre el exceso de reclamos y sobre su negativo impacto en la estética urbana.

Muy similar fue la respuesta de las autoridades locales, responsables de la regulación de la publicidad exterior, de la que obtenían importantes ingresos en forma de impuestos o denuncias. Las solicitudes que se recibían en el Consistorio para hacer publicidad en las calles de la ciudad eran autorizadas o denegadas de forma bastante arbitraria, apoyándose en la laxa legislación existente.

El reto para el Ayuntamiento de Madrid estribaba en tratar de conjugar su obligación de velar por el buen estado de las vías públicas con su necesidad crónica de ingresos, lo que le llevó a tratar de maximizar los impuestos que recibía a través de la publicidad exterior. La documentación analizada no nos permite establecer ninguna relación directa entre la composición política de los distintos ayuntamientos madrileños del periodo estudiado y el aumento exponencial de la publicidad exterior en la ciudad entre 1900 y 1936 . No obstante, ante dicho aumento, sí se ha podido constatar que el criterio restrictivo o totalmente prohibitivo fue imponiéndose a lo largo de los años, lo que no evitó que a la altura de los años 30 la ciudad hubiera sido totalmente conquistada por la publicidad, tal y como revelan los informes consultados. Pero ese juicio cada vez menos permisivo con las cada vez más cuantiosas solicitudes presentadas en el Consistorio, fue defendido fundamentalmente por los técnicos de las distintas dependencias municipales (Tráfico, Vías Públicas, etc.), y no por los cargos políticos del Ayuntamiento.

Finalmente, podemos afirmar que la publicidad exterior no solo transformó la imagen y apariencia de Madrid, especialmente la de los lugares más céntricos y transitados de la ciudad, los más solicitados por este motivo por los anunciantes. También se convirtió en la expresión, sin duda la más vistosa y llamativa, de la nueva cultura del consumo que emergió en aquellas décadas.

\section{Referencias bibliográficas}

ABARCA, E. (1926): Exposición que acompaño al proyecto de Reglamento del tráfico, Madrid, Imprenta Municipal.

AYUNTAMIENTO DE MADRID (1905): Contrata del arriendo para la explotación de veinte aparatos de hierro...., Madrid, Imprenta municipal.

BALANDRÓN PAZOS, A. J. (2007): "Reflexiones sobre la omnipresencia publicitaria en el contexto urbano: la ciudad anuncio" en Balandrón Pazos, A. J.; Martínez Pastor, 
E.; y Pacheco Rueda, M. (dir.): Publicidad y ciudad. La comunicación publicitaria y lo urbano: perspectivas y aportaciones, Sevilla, Comunicación Social, pp. 75-93.

BORÍ, R. y GARDÓ, J. (1936): Tratado completo de publicidad y propaganda I-II, Barcelona, José Montesó (segunda edición corregida y aumentada).

CABELLO LAPIEDRA, X.: “Estilo pirotécnico” en La Época, 12-03-1932.

CHECA GODOY, A. (2015): El cartel. Dos siglos de publicidad y propaganda, Advook, Sevilla.

CRONIN, A. M. (2006): "Advertising and the metabolism of the city: urban space, commodity rhythms" en Environment and Planning D: Society and Space, vol. 24, pp. 615-632.

DE COLUBÍ, J. M. (1928): "Publicidad exterior" en Amengual, B. y otros: Curso de Publicidad y Organización, s.I., pp. 55-75.

EGUIZÁBAL MAZA. R. (1998): Historia de la publicidad, Madrid, Eresma\&Celeste.

ENDERIZ, E.: "El uso y el abuso de los anuncios" en Heraldo de Madrid, 09-08-1927.

GARDÓ, J. (1921): “La técnica de la publicidad” en Actividad, no 7, pp. 5-6.

LAGO, S.: "La evolución artística del anuncio" en La Esfera, 6-01-1917.

MATTELRAT, A. (1991): Advertising international: the privatisation of public space, London, Routledge.

MÉNDEZ VELANDIA, C. A. (2013): “La contaminación visual de espacios públicos en Venezuela" en Revista de Gestión y Ambiente, no 1, vol. 16, pp. 45-60.

MIQUELARENA, J.: “La invasión de los bárbaros del anuncio” en $A B C$, 24-10-1933.

MOSTEIRO, J. "Publicidad y espacio urbano, por una 'grenobilización' de nuestras ciudades" en El País, 14-01-2015.

MUÑOZ MOLINA, A.: "La ciudad tomada" en El País, 19-07-2014 (Suplemento Babelia)

OLIVARES, F. (2009). "Cidade limpa' y la contaminación publicitaria en la ciudad" en ZER, no 26, Vol. 14, pp. 253-275.

PACHECO RUEDA, M. (2014): “Análisis y reflexiones en torno al naming de la Línea 2 del metro de Madrid" en Methaodos, no 2, pp. 201-211.

PORTELLA, A. (2014): Visual Pollution: advertising, signage and environmental quality, Burlington, Ashgate. 
PRAT GABALLí, P. (1917): Una nueva técnica: La Publicidad Científica, Barcelona, Henrich y $C^{a}$.

PRAT GABALLÍ, P. (1933): “El arte y la publicidad” en Nuevo Mundo, 6-01-1933, pp. 3435.

- (1934): Publicidad racional, Barcelona, Juventud.

RODRÍGUEZ MARTÍN, N. (2015): La capital de un sueño. Madrid en el primer tercio del siglo XX, Madrid, Centro de Estudios Políticos y Constitucionales.

WISCHERMANN, C. y SHORE, E. (ed.) (2000): Advertising and the European city: Historical Perspectives, Aldershot, Ashgate. 